\title{
SITUAÇÃO DA NOTIFICAÇÃO EM ESQUISTOSSOMOSE NA GRANDE SAO PAULO (BRASIL), NO PERÍODO DE 1982 A 1983
}

Iracema Amâncio Bezerra*

\begin{abstract}
BEZERRA, I.A. Situação da notificação em esquistossomose na Grande São Paulo (Brasil), no período de 1982 a 1983. Rev. Saúde públ., S. Paulo, 18:386-95, 1984.

RESUMO: Foi feito estudo para determinar os pontos falhos no preenchimento das fichas de investigação epidemiológica em esquistossomose. Com base neste estudo, foi elaborado um roteiro para preenchimento correto das Fichas de Investigação Epidemiológica em Esquistossomose (FE5) e foram desenvolvidas atividades nesse sentido. Os resultados obtidos mostra $n$ que no decorrer do treinamento houve queda sensível de fichas preenchidas incorretamente, on seja, incorreções que eram de $20 \%$ antes das orientaçōes caíram para $8,3 \%$, evidenciando a importância do treinamento de pessoal para melhor rendimento das atividades.
\end{abstract}

UNITERMOS : Esquistossomose, vigilância epidemiológica. Educação em saúde pública.

\section{INTRODUÇÃO}

A história da esquistossomose no Estado de Sāo Paulo mostra, através de diferentes fases, a evolução do conhecimento científico e o reconhecimento da importância do estabelecimento de programas de controle. Essa história desenvolve-se desde o trabalho de pesquisadores como Arantes ${ }^{2}$ (1924); Torres $^{17}$ (1940); Leão de Moura ${ }^{6,7,8}(1945$, 1950 e 1952); Pinto ${ }^{10}$ (1945); Coutinho ${ }^{3}$ (1949); Magalhães ${ }^{5}$ (1949); Lucena ${ }^{4}$ (1950); Antunes $^{1}$ (1952) e Piza ${ }^{11,12,13}$ (1959 e 1960) até o atual trabalho da SUCEN (Superintendência de Controle de Endemias), passando pela fase da Campanha de Combate à Esquis. tossomose (CACESQ). Essa Campanha, que foi instituída em 1968-1969, tinha a atribuição de estabelecer um programa de controle em todo o Estado. Nessa fase foi definida a política sanitária e estruturado o serviço que até então era desenvolvido individualmente. A elaboração da primeira carta planorbídica foi durante a vigência da CACESQ. Em 1976 a CACESQ foi incorporada à SUCEN.

A primeira carta planorbídica do Estado foi elaborada por Piza ${ }^{15}$, em 1972. Nessa carta foram considerados $39,75 \%$ dos municípios existentes no Estado de São Paulo como apresentando espécies transmissoras, distribuidas da seguinte maneira:

\section{Biomphalaria tenagopiilla $36,42 \%$ (208 municípios) \\ Biomphalaria glabrata \\ 3,15\% (18 municípios)}

\section{Biomphalaria straminea}

0,17\% (01 município)

Com os trabalhos desenvolvidos pela CACESQ, e posteriormente pela SUCEN, foram sendo identificadas espécies transmissoras em outros munić́pios. Em 1981, Paraense ${ }^{9}$ descreveu a Biomphalaria occidentalis e com o encontro dessa espécie, no Estado de São Paulo, tornou-se necessária a ela. boração de nova carta planorbídica. As re. giōes de Presidente Prudente e Araçatuba foram as primeiras a serem pesquisadas para esse $\mathrm{fim}^{18}$.

Situação da Grande São Paulo - Rodrigues e Ferreira ${ }^{16}$ descreveram, pela primeira vez, o encontro de Biomphalaria tenagophi-

* Da Divisão de Programas Especiais da Superintendência de Controle de Endemias (SUCEN) - Rua Cardeal Arcoverde, 2878 - 05408 - São Paulo, SP - Brasil. 
BEZERRA, I. A. Situação da notificação em esquistossomose na Grande São Paulo (Brasil), no período de 1982 a 1983. Rev. Saúde públ., S. Paulo, 18:386-95, 1984.

la, em 1966, em Vila Prudente. A coleção hídrica era um buraco de olaria abandonada onde havia dejetos humanos. Em 1968, Piza e col. ${ }^{14}$ descreveram o encontro de $B$. tenagophila positivo para $S$.mansoni nos municípios de Santo André e São Bernardo do Campo, também em buracos de olaria.

A maioria dos focos descobertos posteriormente já foram erradicados, graças a aterros, canalização e outras obras.

Hoje conhece-se B.tenagophila em todos os municípios que compõem a Grande São Paulo. Os criadouros identificados como tipo I, tipo II e tipo III não permanecem sempre nessa classificação, o que exige uma constante vigilância epidemiológica. Os criadouros do tipo I, que apresentam maior potencial de transmissão da doença, encontram-se na sua maioria em favelas situadas nas áreas periurbanas dos municípios.

$\mathrm{Na}$ pesquisa da presença de transmissores, um instrumento muito importante é a Ficha de Investigação Epidemiológica em Esquistossomose - FE5 (Anexo I).

Devido a necessidade de se analisar as FE5 para processar os dados, é feita leitura sistemática das mesmas para encaminhamento, de acordo com a Figura 1.

Fig. 1 - Fluxo das Fichas de Investigação Epidemiológica desde o seu preenchimento nos órgãos geradores da informação até sua chegada ao órgão processador dos dados estatísticos.

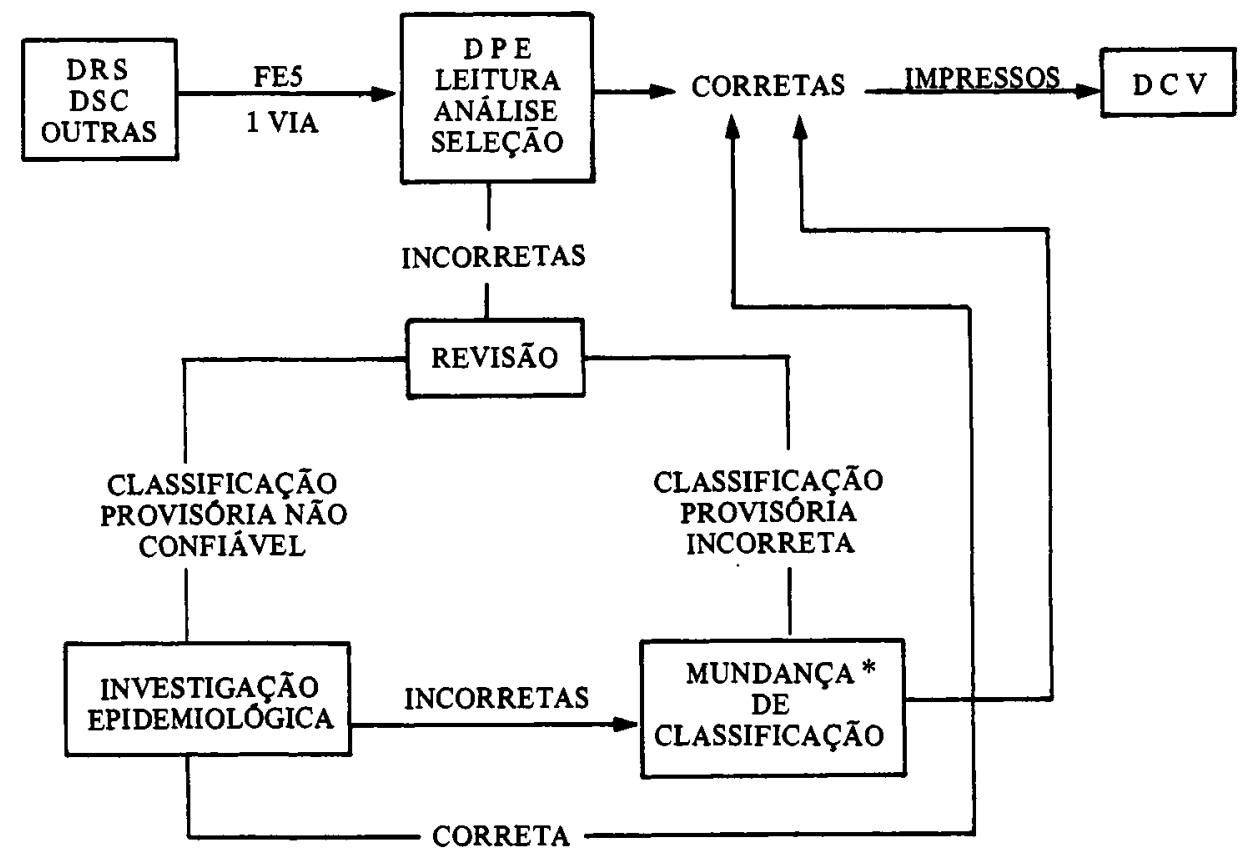

DRS - Departamento Regional de Saúde

DSC - Divisão de Saúde da Comunidade

DPE - Divisão de Programas Especiais

DCV - Diretoria de Combate a Vetores

OUTRAS - Outros serviços de Saúde (Entidades Colaboradoras)
FE5 - Ficha de Investigação Epidemiológica Impressos: SUCEN 271

SUCEN 275

SUCEN 276

* SUCEN 270 
BEZERRA, I. A. Situação da notificação em esquistossomose na Grande São Paulo (Brasil), no período de 1982 a 1983. Rev. Saúde públ., S. Paulo, 18:386.95, 1984.

A partir de 1982, na Divisáo de Programas Especiais - Superintendência de Controle de Endemias (DPE-SUCEN), ao se fazer leitura sistemática das FE5 observou-se fathas no preenchimento das fichas, o que interferia na classificação definitiva das mesmas e acarretava despesas extras, uma vez que na maior parte dos casos havia necessidade de se retornar ao local para refazer as fichas ou para localizar o paciente a fim de complementar as mesmas.

A fim de conseguir uma melhor qualidade no preenchimento da FE5, foi desenvolvido trabalho visando detectar o motivo das incorreções encontradas e estabelecer uma forma de evitar que esses erros acontecessem. Ao mesmo tempo foi estabelecido um alvo a ser atingido, ou seja, que após um período de treinamento de 18 meses, as fichas apresentassem incorreçōes no preenchimento de, no máximo, $3,0 \%$.

Tendo em vista os fatos acima apontados, o presente trabalho tem como objetivo mostrar as deficiências na coleta de dados em Esquistossomose na Grande São Paulo, enfatizando a importância de uma orientação adequada à equipe de saúde responsável por essa atividade.

\section{METODOLOGIA}

Tendo sob nossa responsabilidade a leitura sistemática das Fichas de Investigação Epidemiológica em Esquistossomose, para classificação definitiva da origem dos casos, e visando uma melhor qualidade dessas fichas, passamos a anotar mensalmente, no periodo de abril de 1982 a setembro de 1982, os erros mais freqüentes. Observou-se que esses erros incidiam sempre nos mesmos itens da ficha de investigaç̃̃o.

Após essa cuidadosa observação verificou. -se que a terminologia ou as siglas usadas no preenchimento desses itens eram muitas vezes desconhecidas pelos responsáveis pelo seu preenchimento, por serem próprias das FE5.

A partir dessa observação foi elaborado um roteiro para o preenchimento, leitura $e$ seleção dessas fichas, incluindo alguns con. ceitos mais especificos da terminologia (Anexo II). Este roteiro foi distribuído para todos os serviços de saúde que notificavam a doença. Ao mesmo tempo foram feitas reuniס̄es, palestras e treinamentos não só com - pessoal responsável pelo preenchimento das fichas de investigação, mas com todos os envolvidos nos programas de controle de esquistossomose. As atividades educativas constaram de duas fases: uma teórica e uma prática, esta última visando a familiarização com a FE5 para sua melhor utilização.

0 trabalho foi realizado no período de outubro de 1982 a dezembro de 1983, abrangendo as Secretarias de Saúde do Estado e do Município e outros serviços de saúde que funcionam como entidades colaboradoras no programa de controle de esquistossomose.

\section{RESULTADOS E COMENTÁRIOS}

Na Tabela 1 são mostrados o número e as percentagens de fichas de investigação epidemiológica submetidas à leitura sistemática, feita entre abril e setembro de 1982. Nota-se um decréscimo de incorreçōes que varia de $59,5 \%$ a $11,7 \%$. Essa queda provavelmente ocorreu devido ao contato informal mantido com os responsáveis pelo preenchimento das FE5, uma vez que o programa ainda não estava implantado. Isto explica também os valores mais altos em agosto e setembro, meses em que esses contatos foram praticamente interrompidos para que em outubro fosse implantado o programa.

Na Tabela 2 são apresentadas as atividades educativas desenvolvidas no programa de orientação referente ao preenchimento, análise e seleção das FE5.

Observa-se que as atividades educativas mais freqüentes foram entendimentos e reunið̄es. Nos entendimentos a orientação era feita de um modo informal e sempre que oportuno. As reunióes eram agendadas e com participação, através de convocação, do pessoal de nível técnico para que ele pudesse atuar como multiplicador, super- 
BEZERRA, I. A. Situação da notificação em esquistossomose na Grande São Paulo (Brasil), no período de 1982 a 1983. Rev. Saúde públ., S. Paulo, 18: 386-95, 1984.

visionando a atividade de preenchimento das fichas. As atividades eram desenvolvidas de acordo com solicitação de entidades ou em caso de necessidade de esclarecimento quando julgados necessários pela respon. sável.

Na Tabela 3 são apresentados ó número $e$ as percentagens de fichas de investigação epidemiológica submetidas à leitura e aná. lise durante os meses em que foi feita a orientação técnica e educativa segundo cons. ta na metodologia. Nota-se que a percentagem de fichas incorretas caiu de 18,7 para $1,8 \%$ ultrapassando a percentagem de 3,0\% proposta como objetivo no trabalho.

A Figura 2 apresenta a queda da percen. tagem de fichas incorretamente preenchidas e resume as Tabelas 1 e 3 . Nota-se que, durante o periodo de leitura sistemática, as percentagens se mantiveram altas com exce. ção dos meses em que, embora considerado periodo de treinamento, o programa propria. mente dito não estava ainda implantado e esse treinamento estava sendo feito a nível de contatos informais. Nos meses de agosto e setembro esses contatos praticamente não aconteceram, o que explica a súbita elevação dos percentuais de incorreçōes. Essa interrupção deu-se para que fosse feito um planejamento da implantação do trabalho em outubro. A partir desse mês a queda foi constante, com pequenas variaçðes em alguns meses, devido a intercorrências de ordem administrativa.

TABELA 1

Distribuição das Fichas de Investigação Epidemiológica segundo a qualidade do preenchimento, no período de abril a setembro de 1982, na Grande Săo Paulo

\begin{tabular}{lrrrrr}
\hline & \multicolumn{3}{c}{ Preenchimento } & \\
\cline { 2 - 5 } Mês & Correto & $\phi$ & Incorreto & $\Phi$ & Total \\
\hline Abril & 208 & 40,5 & 305 & 59,5 & 513 \\
Maio & 1069 & 79,5 & 275 & 20,5 & 1344 \\
Junho & 742 & 79,9 & 186 & 20,1 & 928 \\
Julho & 861 & 88,3 & 114 & 11,7 & 975 \\
Agosto & 1361 & 86,8 & 207 & 13,2 & 1568 \\
Setembro & 711 & 81,6 & 160 & 18,4 & 871 \\
Total & 4972 & 79,9 & 1247 & 20,1 & 6199 \\
\hline
\end{tabular}

TABELA 2

Número de atividades educativas desenvolvidas segundo tipo de atividade, durante o período de 1982 a 1983

\begin{tabular}{lrrr}
\hline & \multicolumn{2}{c}{ Ano } & Total \\
\cline { 2 - 4 } Tipo de Atividade & 1982 & 1983 & \\
\hline Entendimentos & 52 & 33 & 85 \\
Entrevistas & 8 & 2 & 10 \\
Palestras & 6 & 10 & 16 \\
Orientação individual & 5 & 7 & 12 \\
Orientação a grupos & 0 & 2 & 2 \\
Reuniőes & 23 & 19 & 42 \\
Adestramentos & 3 & 1 & 4 \\
Total & 97 & 74 & 171 \\
\hline
\end{tabular}


BEZERRA, I. A. Situação da notificação em esquistossomose na Grande São Paulo (Brasil), no período de 1982 a 1983. Rev. Saúde públ., S. Paulo, 18: 386-95, 1984.

\section{TABELA 3}

Número e percentagem de Fichas de Investigação Epidemiológica (FE5), segundo leitura e análise do preenchimento, no período de 1982 a 1983, na Grande São Paulo

\begin{tabular}{lrrr}
\hline Mês & Fichas Lidas & Fichas com Incorreção & Percentagem \\
\hline Out & 1176 & 220 & 18,7 \\
Nov & 689 & 96 & 13,9 \\
Dez & 1441 & 194 & 13,5 \\
Jan & 801 & 93 & 11,6 \\
Fev & 881 & 108 & 12,1 \\
Mar & 1019 & 120 & 11,8 \\
Abr & 1168 & 88 & 7,5 \\
Mai & 1024 & 97 & 9,5 \\
Jun & 1098 & 82 & 7,5 \\
Jul & 573 & 53 & 9,2 \\
Ago & 1254 & 40 & 3,2 \\
Set & 1133 & 23 & 2,0 \\
Out & 826 & 42 & 5,1 \\
Nov & 1307 & 17 & 1,3 \\
Dez & 1200 & 22 & 1,8 \\
& & & 8,3 \\
Total & 15596 & 1295 & 8,3 \\
\hline
\end{tabular}

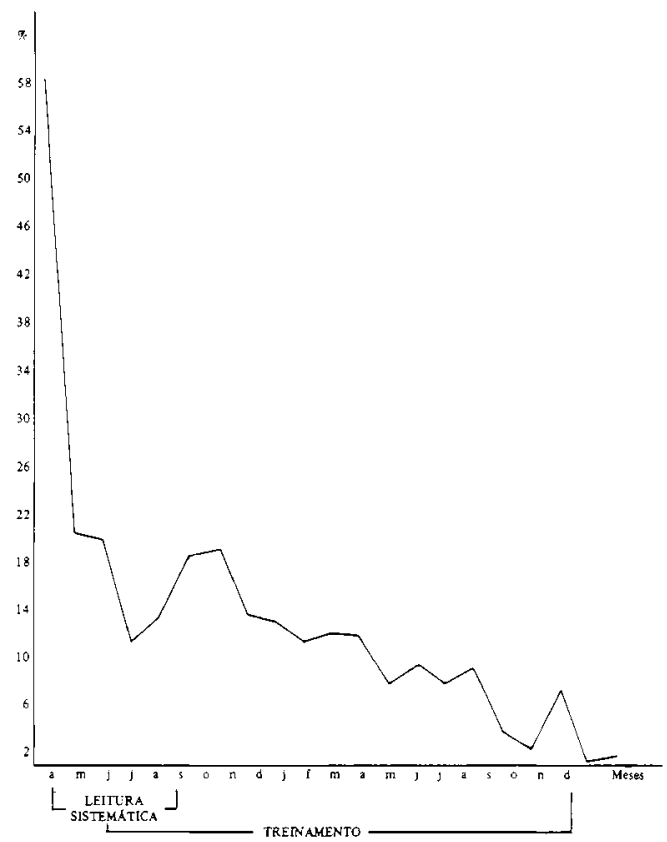

Fig. 2 - Percentagem das FE5 preenchidas incorretamente, no período de 1982 a 1983 , na Grande Săo Paulo.

\section{CONCLUSÃO}

Como resultado do "Programa de Treinamento", observou-se significativa melhora no preenchimento das FE5. Com o decréscimo de incorreçoes que passou de $20,1 \%$ para $1,8 \%$, podemos concluir que os resultados encontrados ultrapassaram a meta proposta.

Diante das atividades e da metodologia utilizada, foi possível interferir na qualidade da coleta de dados, mostrando que por meio de programas de treinamento consegue-se uma sensivel melhora no desempenho de atividades. Em ambos os casos deverá ser enfatizada a importância dos elementos que preenchem as fichas bem como a análise que delas é feita para que seja possível situar São Paulo no contexto de área endêmica, não-endêmica ou potencialmente endêmica.

\section{AGRADECIMENTOS}

Às visitadoras sanitárias da Divisão de Programas Especiais, da SUCEN, que colaboraram na aplicação prática do programa. 
BEZERRA, I. A. Situação da notificação em esquistossomose na Grande São Paulo (Brasil), no período de 1982 a 1983. Rev. Saúde públ., S. Paulo, 18:386-95, 1984.

BEZERRA, I. A. [The position regarding the notification of schistosomiasis in Greater S. Paulo (Brazil) in the period 1982-1983]. Rev. Saúde públ., S. Paulo, 18: 386-95, 1984.

ABSTRACT: A study, giving evidence of inadequate filling-in of file cards used in epidemiological investigation of schistosomiasis, was made. Based on this study a guide to correct filing was prepared and educational activities were developed to avoid the above mentioned failures. Results showed that by means of training, the percentage of mistakes decreased to an appreciable degree. From $20.1 \%$ of incorrectness before the training period, the percentage fell to $8.3 \%$, showing that the quality of the data can be improved by adequate personnel training.

UNTTERMS: Schistosomiasis. Epidemiologic surveillance. Health education.

\section{REFERENCIAS BIBLIOGRĀFICAS}

1.ANTUNES, P.A. de A. A esquistossomíase em São Paulo. Estudo epidemiológico da esquistossomíase na Baixada de Santos. In: Congresso Brasileiro de Higiene, 109, Belo Horizonte, 1952. Anais. Belo Horizonte, 1952. p. 393-7.

2.ARANTES, A. Onze casos autóctones de esquistossomose em Santos. Bol. Soc. Med. Cirurg. S. Paulo, 7(3): 64-5, 1924.

3.COUTINHO, J. de V. Contribuição para o estudo do hospedador intermediário de Schisto. soma mansoni em Santos, Săo Paulo. Rev. clin. S. Paulo, 25 (3/4): 31-8, 1949.

4.LUCENA, D.T. Introdução no país de duas espécies de caramujos transmissores de schistosomiase: Bulinus tropicus (Krauss) e Biomphalaria alexandrina pfeifferi (Krauss). Nota preliminar. Rev. bras. Malar., 2: 278, 1950.

5.MAGALHĀES, Z.P. Esquistossomíase mansoni. Novo foco autóctone em Santos. Rev. Inst. Adolfo Lutz, 9: 15-7, 1949.

6.MOURA, S.A.L. de Esquistossomose mansoni autóctone em Santos. Rev. Inst. Adolfo Lutz, 5: 279-311, 1945.

7.MOURA, S.A.L. de Algumas consideraçōes sobre os focos de schistosomose mansoni de Santos, Estado de São Paulo. In: Congresso Brasileiro de Higiene, 80, Recife, 1950. Anais. Apud D'A VILA, A.C. et al. Situação da esquistossomose no Estado de São Paulo, SUCEN, 1982. [Apresentado ao 2? Encontro sobre Esquistossomose, São Paulo, 1982].
8.MOURA, S.A.L. de Contribuição do Laboratório Regional de Santos na Epidemiologia da esquistossomose mansônica em Santos. Rev. Inst. Adolfo Lutz, 12:97-109, 1952.

9.PARAENSE, W.L. Biomphalaria occidentalix sp. m. from South America (Mollusca basomato phora pulmonata). Mem. Inst. Osvaldo Cruz, 76:199-211, 1981.

10.PINTO, C.F. Sobre um foco de esquistossomíase mansoni em culturas de agriáo (Nas. turtuim officinale) na cidade de Santos. Rev. bras. Med., 2: 820-3, 1945.

11.PIZA, J. de T. et al. A esquistossomose no Vale do Paralba (Estado de São Paulo-Brasil). Observaçóes sobre a doença em alguns de seus municípios e a fauna planorbídica da região. Rev. Inst. Adolfo Lutz, 19: 97-143, 1959.

12.PIZA, J. de T. et al. Vale do Paraíba, foco endêmico de esquistossomose (Estado de São Paulo) importância epidemiológica de $T a$ phius nigricans (Spix, 1827). Arq. Hig. Saúde públ., 25 (83): 35-40, 1960.

13.PIZA, J. de T. et al. Os focos autóctones de esquistossomose no Estado de São Paulo. Arq. Hig. Saúde públ., 25 (86):261-71, 1960.

14.PIZA, J.de T. et al. Papel das olarias na instalação de focos de esquistossomose mansoni. [Apresentado na sessão ordinária de 06.05. 1968 da Associação Paulista de Medicina].

15.PIZA, J. de T. et al. Carta planorbidica do Estodo de São Paulo. São Paulo, Secretaria de Estado da Saúde, 1972. 
BEZERRA, I. A. Situação da notificação em esquistossomose na Grande São Paulo (Brasil), no período de 1982 a 1983. Rev. Saúde públ., S. Paulo, 18:386-95, 1984.

16.RODRIGUES, D.C. \& FERREIRA, C.S. Foco ativo de esquistossomose mansoni no perímetro urbano do município de Sáo Paulo. Folia clin. biol., (35): 94-101, 1966.

17.TORRES, G.D.M. Sobre um caso de schistossomose intestinal autóctone em Santos. Apendicite por Schistosoma mansoni. Arq. Inst. Biol., $11: 579-88,1940$.
18.VAZ, J.F. et al. Resultados preliminares de levantamento planorbídico mas áreas de Presidente Prudente e Araçatuba, Estado de São Paulo. Rev. Inst. med. trop. S. Paulo, $25: 120-6,1983$.

* Trabalho disponível na Biblioteca da SUCEN.

Recebido para publicação em $16 / 02 / 1984$ Reapresentado em 18/06/84 Aprovado para publicaçāo em 17/09/1984 
BEZERRA, I. A. Situação da notificação em esquistossomose na Grande Săo Paulo (Brasil), no periodo de 1982 a 1983. Rev. Saúde públ., S. Paulo, 18: 386-95, 1984.

ANEXO 1

GOVEBNO DO ESTADO DE SAO PAULO

SECRETARIA DE ESTADO DA SACDE

FICHA DE INVESTIGAÇAO L' TRATAMENTO

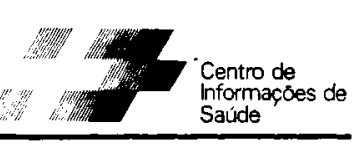

ESQUISTOSSOMOSE

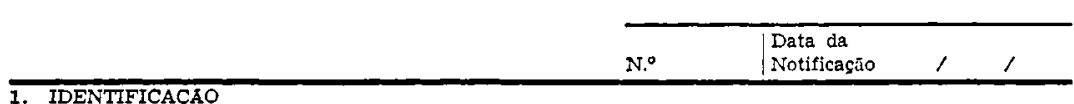

cs

\begin{tabular}{|c|c|c|c|}
\hline \multicolumn{4}{|l|}{ Nome } \\
\hline Idade & Sexo & Naturalidade & Ocupaçăo \\
\hline $\begin{array}{l}\text { 2. RESIDENCIA ATUAI } \\
\text { Fndereço }\end{array}$ & - & Lo & \\
\hline Municipio & U.F. & $\begin{array}{l}\text { Tipo de } \\
\text { coleçóes hidricas }\end{array}$ & \begin{tabular}{|l|} 
Tempo \\
de moradia
\end{tabular} \\
\hline
\end{tabular}

3. RESIDENCTAS ANTERIORES

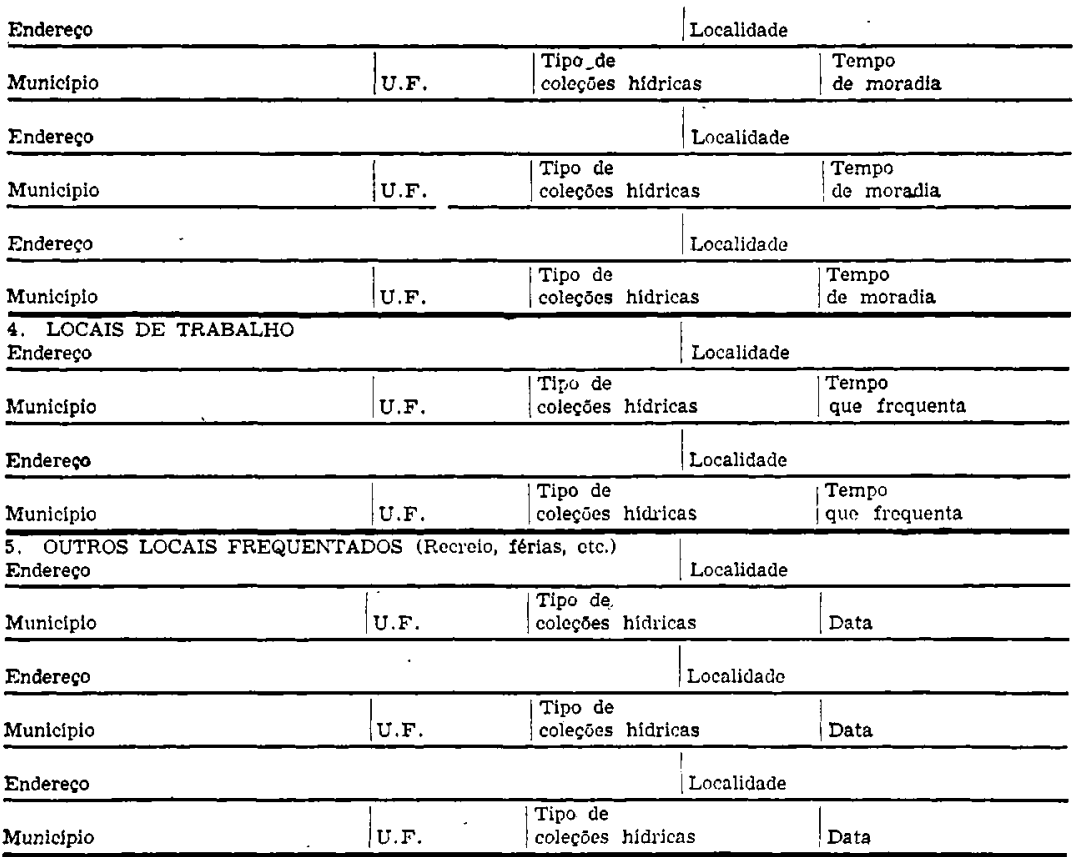

6. COMUNICANTES FAMILIARES E ACOMPANHANTES AOS LOCAIS

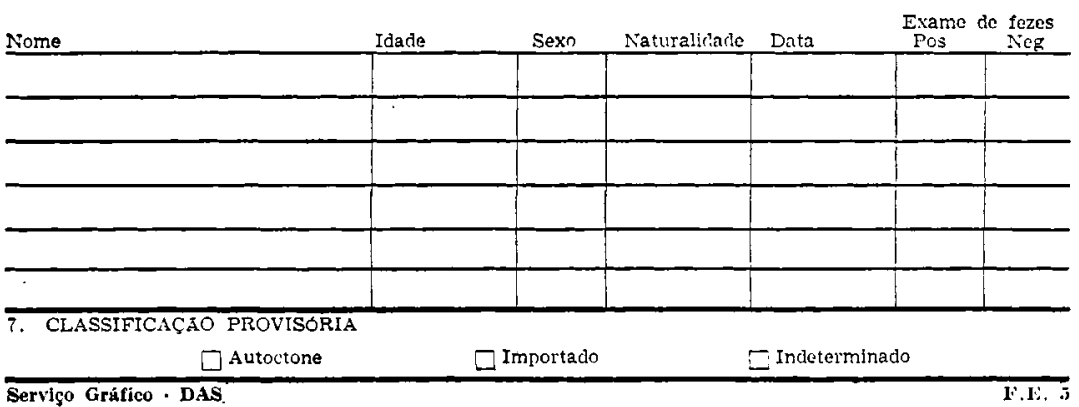


BEZERRA, I. A. Situação da notificação em esquistossomose na Grande São Paulo (Brasil), no período de 1982 a 1983. Rev. Saúde pribl., S. Paulo, 18:386-95, 1984.

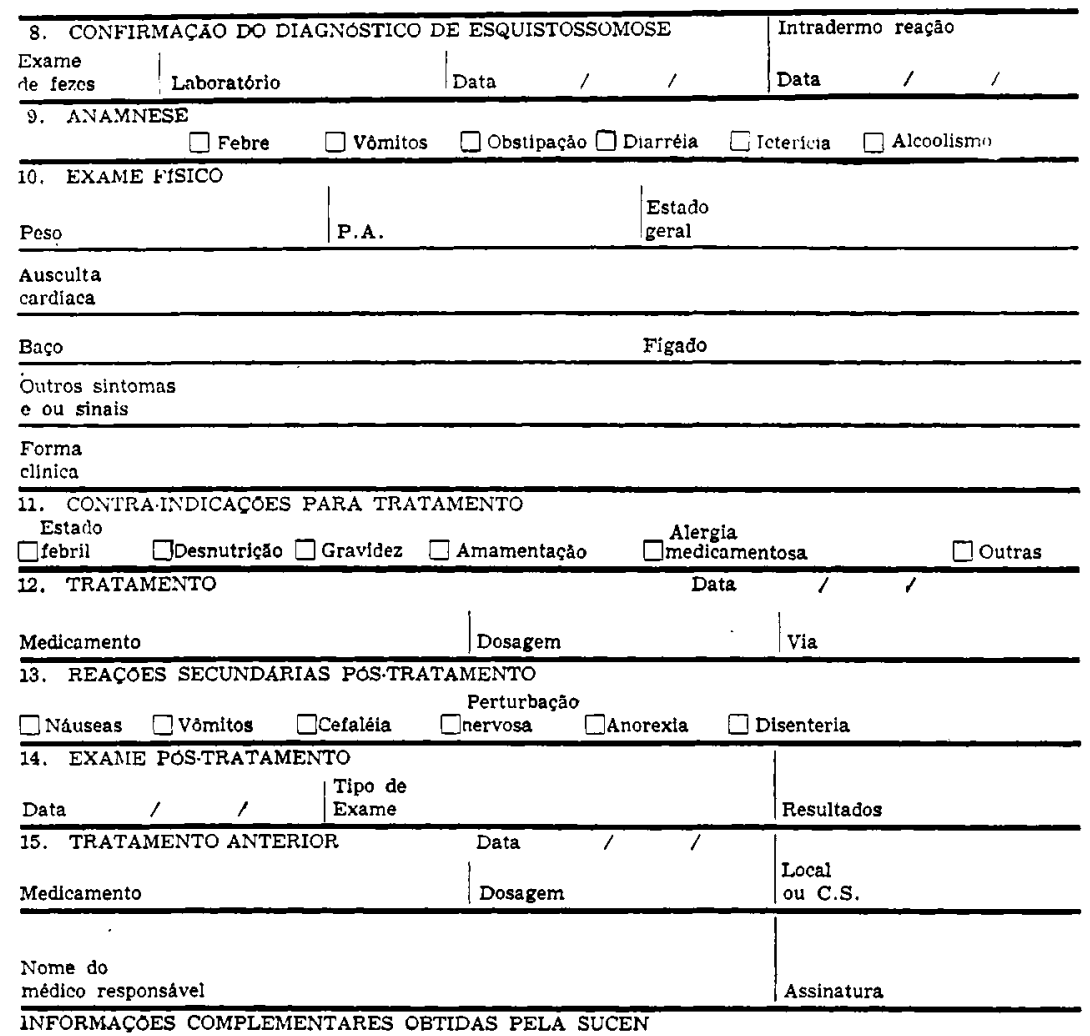

\begin{tabular}{l|l|l}
\hline $\begin{array}{l}\text { Classificação } \\
\text { definitiva }\end{array}$ & $\begin{array}{l}\text { Origem } \\
\text { do caso }\end{array}$ & Data
\end{tabular}


BEZERRA, I. A. Situação da notificação em esquistossomose na Grande São Paulo (Brasil), no período de 1982 a 1983. Rev. Saúde públ, S. Paulo, 18:386-95, 1984.

\section{ANEXO II \\ ROTEIRO PARA PREENCHIMENTO, LEITURA E SELEÇÃO DA FICHA DE INVESTIGAÇÃO EPIDEMIOLÓGICA EM ESQUISTOSSOMOSE}

\section{VERIFICAR se a idade do paciente confere com o tempo de residência em outras localidades (a soma).}

2. CONFERIR se o item "tipo de coleções hídricas" está com informaçð̃es úteis e relacionadas com a transmissão de ESQUISTOSSOMOSE tais como: freqüentou rios, lagoas, córregos, valas, cacimbas, represas, etc. A informação de que se a água que ele consome é tratada (SABESP, mina, etc.) não fornece subsídios para o reconhecimento de como e onde ele adquiriu a doença, uma vez que isto se faz por via cutânea e não oral.

3. DETERMINAR o local exato de nascimento e o tempo em que morou no mesmo, pois a origem é fundamental para a classificação do caso.

4. COMPREENDER a importância de colocar junto ao "endereço atual", um ponto de referência para facilitar a localização do paciente.

5. CONFERIR se consta o nome do laboratório; peso do paciente; a dosagem de medicamento administrado (para controle do medicamento fornecido).

6. VERIFICAR a assinatura, o nome e/ou carimbo do médico.

7. ANOTAR no caso de tratamento anterior (no item 5) data, local, medicamento e a dose dos tratamentos anteriores, sempre que possível, ou apenas os dados fornecidos pelo paciente mesmo que sem comprovante.

8. ORIENTAR os pacientes sobre a maneira como este contraiu a doença e o que deverá fazer para evitar reinfestações.

9. FORNECER o "Certificado de Tratamento" e explicar a importância do mesmo.

10. SEPARAR as fichas incompletas ou de classificação duvidosa para investigar.

CONCEITOS

CASO AUTOCTONE - É o caso procedente do próprio Estado de São Paulo, inde. pendente do município.

CASO IMPORTADO - É todo caso procedente de outro Estado de área endêmica.

CASO INDETERMINADO - E todo caso de área endêmica de outros Estados e que tenha freqüentado ou resida em áreas de focos do Estado de São Paulo.

TIPO 1 - Criadouros de grande importância epidemiológica: são aqueles que recebem dejetos humanos e também são freqüentados pelo homem.

TIPO 2 - Criadouros de média importância epidemiológica: são aqueles que embora recebendo dejetos humanos difícil ou raramente são freqüentados pelo homem.

TIPO 3 - Criadouros de pequena importância epidemiológica: são constituídos por aqueles que embora freqüentados ou não pelo homem não recebem dejetos humanos e, portanto, muito dificilmente os caramujos poderão ser infectados.

FOCO - Criadouros onde tenham sido encontrados exemplares das espécies transmissoras eliminando cercárias de Schistosoma.

FOCO SOB CONTROLE - Aquele que, mesmo tornado negativo, continua em condições de se reativar, devendo, portanto, periodicamente, ter a sua popu. lação planorbídica examinada.

FOCO EXTINTO - Todo local onde definitivamente não apresente condições para a criação de caramujos ou que tenha sido realizada alguma obra de saneamento (aterro, canalização, revestida de concreto e outros). 